Revista de la red interuniversitaria de estudios sobre las literaturas rioplatenses contemporáneas en Francia

19 | 2018

La rebelión de los hijos: el judaísmo en la literatura latinoamericana contemporánea entre tradición y asimilación

\title{
Presencia de lo judío en la poesía argentina contemporánea
}

Geneviève Fabry

\section{OpenEdition}

\section{Journals}

Edición electrónica

URL: http://journals.openedition.org/lirico/6529

DOI: $10.4000 /$ lirico.6529

ISSN: 2262-8339

Editor

Réseau interuniversitaire d'étude des littératures contemporaines du Río de la Plata

Referencia electrónica

Geneviève Fabry, « Presencia de lo judío en la poesía argentina contemporánea », Cuadernos LIRICO

[En línea], 19 | 2018, Puesto en línea el 21 enero 2019, consultado el 30 abril 2019. URL : http://

journals.openedition.org/lirico/6529; DOI : 10.4000/lirico.6529

Este documento fue generado automáticamente el 30 abril 2019.

\section{cc) (†)}

Cuadernos LIRICO está distribuido bajo una Licencia Creative Commons Atribución-NoComercial-

SinDerivar 4.0 Internacional 


\title{
Presencia de lo judío en la poesía argentina contemporánea
}

\author{
Geneviève Fabry
}

1 En un artículo publicado en 1989, Edgar Morin declaraba que la palabra "judío" había dejado de poder usarse como sustantivo en el contexto moderno.

Asimilado para unos, inasimilable para otros, el judío siente en sí mismo una extrañeza, y en relación con la religión de Moisés de la cual se distanció, y en relación con el mundo de los gentiles, en el que persisten mil formas de rechazo. Así está obligado a una identidad doble y turbia. El nombre judío ha dejado de ser para él un sustantivo, es un adjetivo que lo ata a un pasado de tradiciones perdidas y de persecuciones que constantemente pueden volver a nacer. $(212)^{1}$

2 Al contrario del francés, el castellano permite la sustantivación del adjetivo -lo judío- y así abre la posibilidad (al nivel lingüístico por lo menos) de un planteamiento amplio que considera las tres direcciones que Levinas estimaba pertinentes para definir la condición judía: primero, en relación con una religión ("sistema de creencias, de ritos y de prescripciones morales fundados en la Biblia, en el Talmud, en la literatura rabínica, muchas veces combinados con la mística o la teosofía de la cábala" , 42); en segundo lugar, con relación a una cultura, derivada de la religión; en tercer lugar, con relación a una "sensibilidad difusa hecha de algunas ideas y recuerdos, de algunas costumbres y emociones, de una solidaridad con los judíos perseguidos en tanto judíos" (42).

En su libro Écriture et identité juive en Argentine dans la transition démocratique (2010), Viviana Fridman examina el peso la presencia de lo judío en un corpus de seis novelas de los años 80 y 90 (además de Los gauchos judíos de Gerchunoff, 1910) y concluye lo siguiente. Primero, lo que enfatizan estas novelas es una cultura judía de lo cotidiano en la que las fiestas rituales (especialmente la pascua), la gastronomía y el cruce con las lenguas judías (hebreo, yiddish y sefardí) son marcadores importantes, al revés del judaísmo como religión casi ausente del corpus: "la casi ausencia de la religión en un corpus literario que atañe a la identidad judía es un indicio significativo de una forma muy laica de concebir la judeidad" (Fridman 214). ${ }^{2}$ El segundo elemento recurrente es el de la memoria que se plasma en una "búsqueda genealógica" (215). Muchas veces las tramas familiares conectan la pequeña historia de la familia con la Historia grande; muy recurrente es la 
referencia al Holocausto que constituye, según Robin, un "zócalo discursivo del imaginario judío contemporáneo" (232). ${ }^{3}$ En tercer lugar, la narrativa judeoargentina estudiada por Fridman desmiente la ficción nacionalista homogeneizadora que ha constituido el discurso dominante en la Argentina desde el comienzo del siglo XX. La judeidad aparece como "exterioridad y marginalidad" $(252)^{4}$ con relación a la identidad nacional, pero la tensión entre judeidad y argentinidad es compleja: cada uno de los narradores estudiados propone una síntesis sui generis: "el trabajo sociogramático de los textos literarios examinados se sitúa en una superación de [la] oposición [entre asimilación y gueto], en la figura de la hibridez"5 (263).

4 En el marco del presente estudio, cabe preguntarse pues si se observan estos mismos rasgos en un corpus poético. Aunque se hagan algunas referencias a la poesía anterior (especialmente la de Gelman de fines del siglo XX), quisiera examinar aquí poemarios escritos por tres escritoras argentinas nacidas alrededor de 1950 que reconocen una herencia judía en su historia personal: El ghetto de Tamara Kamenszain (2003), Canto errante y Memorial de agravios (2002) de Mercedes Roffé (2002) y Ética demostrada según el orden poético de Liliana Lukin (2011). En este corpus, lo que predomina es una sensibilidad difusa, que relaciona el gesto de la escritura con la memoria de un aspecto del legado religioso y cultural judío que se trata al mismo tiempo de reconocer como propio y de problematizar. En Kamenszain, la tematización de la identidad y el relato genealógico son explícitos y centrales; en Roffé, lo judío interviene más específicamente en el proceso mismo de la escritura y de la determinación genérica del poemario; finalmente en Lukin, lo judío se inscribe implícitamente como desplazamiento e inscripción sesgada de una tradición intelectual occidental. Pero vayamos por partes.

\section{EL gHETTO (2003) DE TAMARA KAMENSZAIN}

La trayectoria literaria de Kamenszain (1947-) se abre con un libro de poemas en prosa, De este lado del Mediterráneo, que esboza el escenario genealógico del que brota la escritura. Dedicado al abuelo que le contaba narraciones procedentes de tradiciones judías, el libro evoca los modelos tutelares de la escritura, haciendo hincapié en la figura bíblica de Ruth. Ruth la moabita acompaña a su suegra a Canaan y allí se casa con Booz, adoptando su fe. Desde un punto de vista simbólico, Ruth inscribe la errancia y la extranjería en la identidad judía en una época antigua, anterior al exilio babilónico. En "Retorno II", dice el yo lírico:

En esta tristeza de no ser más la que sentándose en las rodillas de un abuelo escuchaba la historia de la moabita Ruth está la alegría de encontrar en cada objeto un indicio de esa historia, el asombro de saber que la poesía no hace más que continuarla porque es a la vez madre e hija de la moabita Ruth (Kamenszain, La novela 80). ${ }^{6}$

6 La figura masculina garantiza pues el continuum de la tradición al transmitir "historias" a la niña. Pero ésta se las apropia mediante la poesía que una manera de desregular el paso transgeneracional: la poesía es "a la vez madre e hija de la moabita Ruth"; la poesía como "madre" permite desarrollar la búsqueda genealógica hacia el pasado pero abre también un futuro imprevisible, abierto a la novedad que representa la "hija".

7 Esta exploración bi-direccional de la genealogía y esta tensión entre comunidad y extranjería, o constricción y libertad, están en el centro del poemario que Kamenszain publica treinta años después: El ghetto (2003). Recordemos que la palabra viene del 
italiano y se refiere a la "Judería marginada dentro de una ciudad" (DRAE, acepción 1). ${ }^{7} \mathrm{El}$ margen se incribe paradójicamente "dentro de" la ciudad, no fuera, como para indicar que se tensionan el margen y el centro en una relación paradójica. Es esta paradoja la que explora este poemario de 2003.

El libro va dedicado al padre difunto de la autora, según reza la dedicatoria:

In memoriam Tobías Kamenszain

En tu apellido instalo mi ghetto (265)

El ghetto es en principio el lugar que le es asignado a una comunidad minoritaria, no se escoge y menos aún se escoge a título individual. La primera persona del verbo "instalo" da muestra de la elección activa del sujeto de la escritura que asume su linaje biológicocultural y lo transforma en lugar de subjetivación y de libertad, estos es, de escritura. Desde los primeros poemas, el sujeto de la escritura se designa negativamente frente a figuras, a modelos masculinos: los traductores de Toledo y Avicena en el primer poema ("Prepucio", 271), Trotsky (evocación enigmática en "Escudo de David" p.273), Buber ("Solideo", p.274-6). Este tercer poema se cierra con la determinación de la hablante lírica:

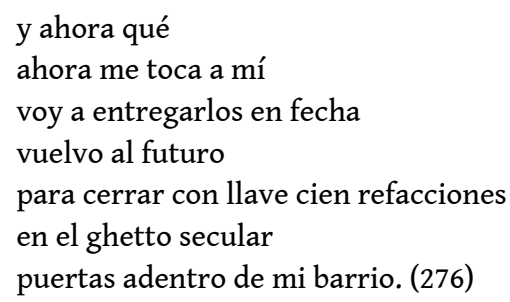

"Vuelvo al futuro", o sea, hago de la memoria no un tema elegíaco para la melancolía o la nostalgia (estas dos palabras, sí, aparecen en De este lado del Mediterráneo, poemario de Kamenszain publicado en 1973), sino un camino para negociar una repetición, un retorno que sea también una apertura a lo por venir. Podemos destacar las estrategias siguientes para enfatizar este peculiar modo de memoria.

11 En primer lugar, el poemario le quita todo pathos a esta autoinscripción en el "ghetto". La emigración de los bisabuelos "de Rusia para acá" (277) es una historia repetida que le suena al yo lírico como "vinilo rayado de Beatles" (277). Su propio exilio mexicano la lleva a relativizar la experiencia del exilio:

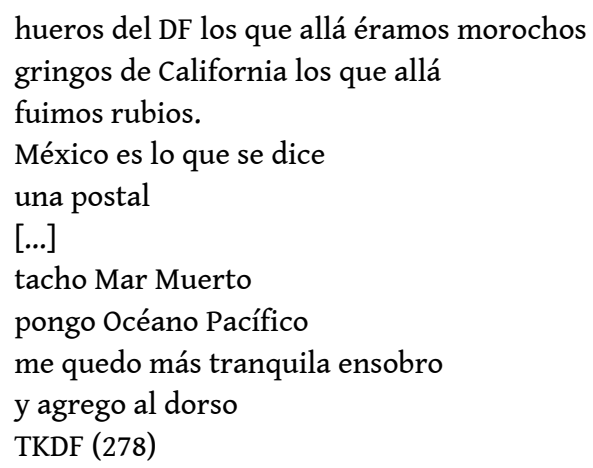

La firma situada (TK en DF) parece suturar, aunque sea provisionalmente, los afectos negativos vinculados a la experiencia del exilio. Este rechazo del pathos ${ }^{8}$ culmina con el último poema del libro que evoca un día de excursión a Río de Janeiro. El grupo de "judíos" (como reza el título) o de "portuñoles" (299) parece diluirse en el ambiente festivo del carnaval: 
una fauna dejada de la mano de Dios

los que bailan y los que ven bailar

inauguramos el mismo carnaval (299)

Este poema final da una vuelta de tuerca al tema de la identidad al desplazarla al terreno de la fiesta y del carnaval y, más sutilmente, a la circulación intertextual de la gran poesía latinoamericana. De hecho, Adriana Kanzepolsky señala que el verso final del último poema “'Aquí llegamos, aquí no veníamos' abre 'Aquí llegamos', poema de Fragmentos a su imán, el último libro de Lezama, sobre el que Kamenszain ha vuelto con cierta frecuencia" (112). El cierre se hace apertura. La segunda estrategia consiste en tratar del duelo del padre difunto (anunciado desde la dedicatoria pero que se tematiza en la segunda parte del libro) en una tonalidad marcadamente antimelancólica'. Se trata, ya lo hemos dicho, de volver al futuro; esto significa para la hija enlutada la búsqueda de un camino vital. En el poema "Árbol de la vida", queda claro que el rito no sirve ni como consuelo ni como hermenéutica del duelo: la oración del kaddish se reduce a una página arrugada:

cuando piedra sobre piedra entierro

mal traducida la fotocopia del kaddish

en el fondo de mi cartera qué me dice

la tradición a expensas de tu muerte

una verdad menos que revelada

no hay rabino que ayune ganas de saber

no hay duelo lo que estoy viendo es lo que se ve (293)

[...]

verde sobre verde avanza el paisaje de todos

[...]

Mi duelo, lo que estoy viendo

será de aquí en adelante este verdor que te dedico,

Hoy florecen en las copas de los árboles todas mis raíces. (294)

Lejos de la "piedra blanca sobre la piedra negra" de Vallejo ${ }^{10} \mathrm{o}$ del himno desgarrado que Allen Ginsberg le dedica a su madre, el entierro evocado aquí es florecimiento y verdor. Vivir la tradición es vivir la muerte del padre, esto es, celebrarla a través de lo que hay: el paisaje (verde sobre verde) y la escritura que opera la reversibilidad entre raíces y flores, es decir, que permite volver al futuro. La tensión entre tradición y apertura al futuro no está ausente de la poesía de otra escritora argentina que se va a estudiar a continuación.

\section{CANTO ERRANTE Y MEMORIAL DE AgRAVIOS (2002) DE MERCEDES ROFFÉ}

Mercedes Roffé, nacida en Argentina en 1954, vive en Nueva York desde 1995 ; es editora, traductora y poeta. Entre sus poemarios más importantes se pueden citar: Canto errante (2002), Mémorial de agravios (2002), El tapiz (1983), Cámara baja (1987), La ópera fantasma (2005), Las linternas flotantes (2009) y Diario ínfimo (2016). Al periodista que la interrogaba acerca de su "ascendencia sefardí [que] implica por sí misma una mezcla" ya que se trata "de una tradición judía muy estrechamente en contacto con la cultura árabe de Marruecos"11, Mercedes Roffé (1954-) respondía lo siguiente:

Tengo la sensación de que ese contacto con el judeo-español, a través de la comunidad, me ha hecho tener una especie de vivencia casi cubista de la lengua: una percepción simultánea de realidades y estados de lengua que no sería habitual ver confluir al mismo tiempo, en el mismo lugar. Cuando era chica, el judeo-español era una lengua de nuestra casa, del ámbito de lo privado [...] (Roffé en Laboy, 238). 
Le la poeta subraya el hecho de que se siente «profundamente inclinada a apoyar [... la conservación de todo el bagaje cultural ya existente (libros, canciones, fotos, testimonios, relatos de costumbres, refranes, recetarios, la lengua misma...), pero no a producir [ella] algo nuevo en esa lengua » (239) como lo hiciera Juan Gelman en Dibaxu (1994). De ese bagaje, destaca especialmente, para la poesía, la tensión entre inscripción en la tradición y expulsión.

Se encuentra en Las linternas flotantes, como en su primer poemario, Canto errante "la confrontación de la agonía del lenguaje con la plenitud a menudo arrasadora de los poemas fundacionales, volviéndonos a mostrar los deslindes de una historia en la cual la condición insalvable para nombrar el amor es primero haber nombrado su condena". ${ }^{12}$ Estas palabras del poeta chileno Zurita concuerdan completamente con Las linternas flotantes, poemario en el que una intertextualidad ${ }^{13}$ compleja evoca a la vez la creación del mundo, el surgimiento del bien y del mal, y la escritura del poema que es "el ritmo de lo otro en mí" (Roffé, 2009:49).

El poemario consta de veinte poemas de extensión variable y de versos libres, seguidos de un epílogo. El primer texto evoca una ensoñación en la que el yo lírico se propone "Residir la noche toda en la pura presencia de la letra/ Aleph Beth Yod" (9) ${ }^{14}$. Los ecos cabalísticos de este texto inaugural son confirmados más adelante, especialmente en el poema XII en el que la expulsión del sujeto lírico remite al exilio primordial:

[...]

Esfera es

el abrazo ése que me excluye

Esfera-Tierra Prometida

Esfera-patria y memoria de la patria

de la que todo me expulsa y me destierra

Esfera-origen y fin

Esfera-estrella y brújula y lazarillo

y una luz en el centro.

Ésta es mi alma

Éste mi soplo en tu soplo.

Centella de lo que solo existe

en la vasija que eres.

[...] (Roffé, 2009: 43).

El vocabulario de la expulsión, de la centella y de la vasija apunta a la doctrina del Tsimtsoum, del que Isaac Louria había dado una primera formulación en el siglo XVI. Este término evoca la retractación de Dios que, al retirarse, crea un vacío susceptible de volverse espacio de acogida del mundo creado. A esta primera etapa sucede una segunda, llamada generalmente la ruptura de las vasijas. De hecho, «después del Tsimtsoum, la luz divina irrumpe en el espacio vacío bajo la forma de una rayo en línea recta. ${ }^{15}$ Más adelante las luces se difractaron y fueron contenidas en vasijas sólidas, lo que implicó el hecho de que algunas "centellas" quedaron pegadas a los fragmentos de vasijas rotas (Ouaknin 33). Cuando Adán separó la fruta del árbol en el jardín de Edén, multiplicó los efectos del rompimiento de las vasijas y así aplazó e hizo más compleja la tarea de reparación que les incumbe a los seres humanos.

La referencia cabalística se enlaza con una reescritura de las páginas iniciales del Génesis. Así en el poema VI :

La luz se hizo.

¿Quién ha de dudarlo?

Y los pastos y los cielos y los mares. 
Sutil aquel que separó

el azul del azul

el día de la noche

el verde metálico del atardecer

del verde-vida del prado.

[...] (Roffé, 2009: 25)

Al contrario del libro bíblico, no se destaca el sujeto divino del acto creador. Los poemas siguientes evocan una creación que oblitera el episodio de la serpiente y de la caída (“Caída no hubo./[...] Ni aciago Demiurgo", Roffé, 2009: 33) y vuelve improbable la existencia del creador $^{16}$, salvo si se considera la hipótesis del Tsimtsoum, ya mencionada. En el vacío así creado, aparece un espacio fecundo :

la nada plena

la suspensión total

en el dorado seno de todo lo creado

un hiato

- - contundente y fecundo

Esa ausencia absoluta

- -lugar de encuentro » (Roffé 2009: 47).

Este lugar de encuentro será por supuesto el poema, atravesado también por el soplo y el vacío, y las fuentes diversas de las espiritualidades del mundo. Como indica el título, las tradiciones orientales no están ausentes : las linternas flotantes remiten historicamente al homenaje religioso hecho por los hinduistas a la diosa-madre Gangâ, al dejar flotar sobre el río sagrado pequeñas linternas. Las referencias al "loto originario" (poema VI) o al jasmín nos recuerdan esta misma veta oriental, mientras que el poder verbal del poema, se evoca mediante la teoría del ritmo de Pitágoras, teoría que enlaza nuevamente los planos cósmico y poético, como en el poema XV, verdadera arte poética del libro:

[...]

El poema es el ritmo de lo otro en mí

más allá de mí, siempre, más allá,

donde mi silencio se topa con tu ritmo

y repercute en mí, que solfeo en el poema

un ritmo numinoso,

cifra que hace eco en el eco

que es el cuerpo verdadero

-lo numinoso en ti y en mí-

el ciclo de las esferas tocándose y abandonándose

-alejándose, sí, una de la otra,

pero desasiéndose de sí también

cada cual

en su dorada, fecunda negligencia. (Roffé 2009: 49)

Última pieza del edificio intertextual: el fragmento de la República de Platón, citado textualmente en el poema XVIII, que retoma el famoso relato de Er, guerrero que tuvo el privilegio de ver los infiernos y de relatar su experiencia a los vivos. Se trata de la única cita textual. Las otras inserciones intertextuales se articulan generalmente alrededor de ramificaciones léxicas o de inversiones semánticas, como en el caso de la referencia a la caída.

En varios poemas, el yo lírico especifica que "No hubo Caída" $(33,61)$. Sin embargo, el mal es un dato, a la vez empírico y filosófico, del que la constatación espantada recorre todo el poemario: 


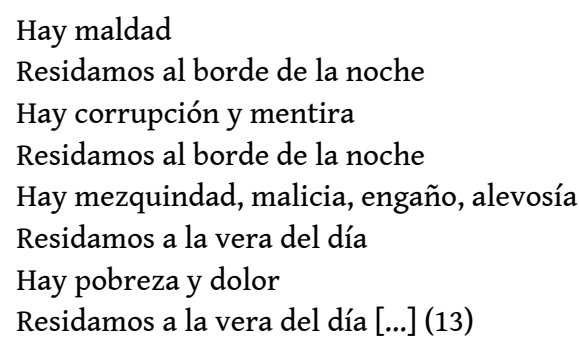

El mal, a pesar de su omnipresencia, es incapaz de frenar el impulso contemplativo del yo lírico, impulso que es primero el de morar, después el de resistir:

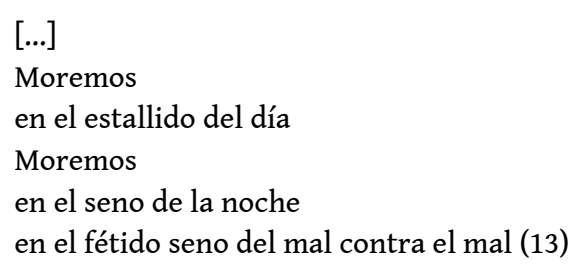

El final del poemario de Mercedes Roffé consagra la bondad de la creación ${ }^{17}$, no porque el mal esté ausente, sino porque acoge en su seno la posibilidad de una palabra que recuerda y potencia su dimensión creada y creadora. Las linternas se topan con el oleaje de la malicia y la alevosía, pero flotan e iluminan. El mito bíblico de la creación es evocado pero mantenido como en suspenso, en el entrecruzamiento intertextual que genera una significación futura; solo importa el espacio de resonancia del poema, "docta cadencia, felicísima caída en el cruce/ de todos los sentidos" (50). Las variantes cabalísticas del mito de la creación hacen hincapié en la dialéctica entre creación y expulsión, una dialéctica que volvemos a encontrar en la poesía de Liliana Lukin.

\section{LA ÉTICA DEMOSTRADA SEgÚN EL ORDEN POÉTICO (2011) DE LILIANA LUKIN}

En un artículo firmado por Rita Saccal, quien intenta elaborar una nómina de los escritores argentinos de origen judío, Liliana Lukin aparece como representante de la tercera generación, como Tamara Kamenszain. ${ }^{18}$ Una parte significativa de su obra gira alrededor del cuerpo, también el cuerpo sometido al poder de la represión (como en Descomposición, 1986) o también el cuerpo erótico (como en Retórica erótica, 2002).

El libro que publica en 2011, Ética demostrada según el orden poético, tiene varias líneas de contacto con Memorial de agravios. Podríamos destacar dos de ellas: el paradigma cultural y epistémico barroco, así como el predominio del sueño. La palabra «Sueño » abre el poema inaugural y también el propio libro ya que la portada consta de un triple motivo. El primero es una reproducción de un grabado de Goya: "El sueño de la razón produce monstruos"19, el segundo ofrece un recorte del Agnus Dei de Zurbarán, mientras que el tercero presenta el emblema de Baruch de Spinoza. Spinoza es el autor de la Ética demostrada según el orden geométrico (1677): Liliana Lukin nos ofrece aquí una reescritura poética del tratado de Spinoza, invirtiendo la relación más habitual entre poesía y filosofía. Desde Heidegger hasta Alain Badiou, la poesía ha sido considerada como un objeto por la filosofía que le aplica un metadiscurso que de alguna forma supedita la poesía a la elaboración conceptual del filósofo. Con Lukin, se despliega una poesía meditativa que ofrece «citas » $\mathrm{y}$ «comentarios » del libro póstumo del gran filósofo holandés de origen sefardí. Empleo adrede los términos de "citas" y "comentarios" 
porque creo que la empresa de Lukin, en este libro, es bastante similar a la que hiciera Gelman en los años 80 con sus citas y reescrituras de místicos españoles, interpolados con citas de tango, entre otras fuentes. Pero existe una gran diferencia entre estos dos escritores argentinos: los libros de Gelman eran alegóricos (aunque la alegoría se decantaba en símbolo), la mística evocaba un "aquello" que designaba lo perdido, el exilio, el duelo y su "presencia ausente" en el poema. ${ }^{20}$ El libro de Lukin no presenta ningún código alegórico: la reescritura gozosa de la Ética no remite al lector a otra cosa que no sea el diálogo en sí entre los dos autores cuyas voces se entrelazan en la dicción muy particular del yo lírico.

Introducido en el primer poema por el título "Demostración (habla Baruch de Spinoza)", el yo lírico cita al filósofo al comienzo de cada "libro" (hay cinco "libros" y un "apéndice" en el poemario) pero después elabora su propia meditación enhebrando retazos de la Ética alrededor de sus propios hilos: el sueño, el cuerpo y el pensamiento. De la misma manera que el libro desdice una enunciación binaria (el yo lírico es y no es al mismo tiempo Lukin y Spinoza), se opone a todo dualismo, especialmente el que separa cuerpo y pensamiento.

\section{XIX}

Puedo todo lo que mi cuerpo

piensa, aunque nadie sabe

lo que puede un cuerpo.

Así, sueño que puedo

unir lo que estaba separado,

dar con la palabra

que cose sin más goce que dar:

el plato y el hambre con el vaso,

la sábana con el cuerpo,

el cuerpo

con la casa, y la palabra

con la voluntad.

Sueño que puedo unir lo que he

soñado: las buenas pasiones con el acto,

lo humano en pacto de amistad.

(51, énfasis en el original que corresponde a una cita del libro de Spinoza)

En oposición al dualismo cartesiano, ${ }^{21}$ Spinoza afirma la unicidad del ser, el carácter inseparable y unido del cuerpo y del espíritu. ${ }^{22}$ La unidad intrínseca del ser humano apunta también a una unión íntima entre vigilia y sueño, entre pensamiento y gozo. Así lo afirma el poema XXIV:

\section{XXIV}

Todas las partes de mi cuerpo sueñan:

al soñar gozo tanto como al estar

despierto, por eso insisto en una misma

melodía, sabiendo que es preciso

cautela para actuar.

Escribo: o bien callar o bien decirlo todo.

Y mi cuerpo goza cuando pienso. (56)

31 Jacques Ancet, el traductor de Lukin al francés, nos recuerda que

la poesía de Liliana Lukin se sitúa de entrada en esta tradición de la meditación de la que Unamuno en su tiempo se reclamaba también y que, de los místicos españoles, de los «Metafísicos » ingleses a Eliot, Cernuda o Valente, pasando por Leopardi, Wordsworth, Coleridge, Hopkins, Rilke, Mallarmé o Borges, tiende y contra todos los dualismos que nos parasitan, a sentir el pensamiento y pensar el sentir (10, énfasis en el original). 
¿Qué queda de la identidad judía en este ejercicio de reescritura que hace suya la concepción gozosa del pensamiento como acción de un cuerpo pensante? Podríamos responder: un gesto, el gesto de la firma abiertamente apócrifa. En efecto, el primer poema "Demostración (habla Baruch de Spinoza)" se repite exactamente igual al final del libro pero esta vez desprovisto del título y de su firma. En un breve ensayo titulado "El círculo de tiza del Talmud", Támara Kamenszain nos recuerda que los talmudistas se comprometían a leer sólo la Biblia y sus comentarios, los cuales eran anónimos y se almacenaban en la memoria primero oral y luego escrita de las comunidades judías. En ese contexto, la obra de Spinoza representa una subversión considerable:

Pecador por excelencia, [Spinoza] saltó el círculo de tiza para acceder, a través de su nombre, a la universalidad. [...] Quizás no fue por alejarse de la "verdad" bíblica que se acusó a Spinoza de herejía (acercarse y alejarse de esa verdad era un peligroso juego que los talmudistas -escritores al fin- no desconocieron), Spinoza comió otra manzana prohibida: la del goce de firmar. Firma, universalidad, traducción: Spinoza, por fin, volvió traducibles Las Escrituras. (216)

[...] Spinoza aclaró Las Escrituras. Así devino filósofo y fundó -como Borges para la literatura argentina- la universalidad. Refinada por un trabajo anónimo, aquella materia gramatical puede ahora salirse del gueto y viajar más allá de los límites de su propia lengua. (217, subrayado mío)

En el libro de Lukin, Spinoza -el expulsado- es el nombre del gueto como lugar paradójico de inscripción (firma) y expulsión (traducción). Cada uno de los tres poemarios estudiados aquí esboza a su manera el camino de salida de una identidad judía concebida sobre todo en términos de genealogía y memoria de un peculiar modo de poetizar y pensar, una tradición que genera una inscripción paradójica, entre adopción y salida. Podríamos aplicar a la poesía de Liliana Lukin y Mercedes Roffé este comentario de Huberman relativo a Kamenszain: "Tanto su poesía como su ensayística problematizan los conceptos de afiliación y pertenencia a la tradición al formular una judeidad que se reconoce foránea, ajena a todo código tradicional de representación. Paradójicamente, justamente por eso, su escritura se inscribe en la tradición judía -entendida aquí como la tradición de la pregunta- y cuestiona sus límites desde dentro" (107).

\section{BIBLIOGRAFÍA}

Fabry, Geneviève. Las formas del vacío. La escritura del duelo en la poesía de Juan Gelman. Amsterdam/ Atlanta, Rodopi, 2008.

Fridman, Viviana. Écriture et identité juive en Argentine dans la transition démocratique. Paris, $\mathrm{H}$. Champion, 2010.

Huberman, Ariana. "Desde las roturas: Memoria, judeidad y extranjería en Tamara Kamenszain”. Hispamérica, Año 34, No. 102 (Dec., 2005), p. 107-113.

Kamenszain, Tamara, La novela de la poesía. Poesía reunida. Con prólogo de Enrique Foffani, Buenos Aires, Adriana Hidalgo, 2012.

Cuadernos LIRICO, 19 | 2018 
--- "El círculo de tiza de Talmud", Historias de amor (y otros ensayos sobre poesía), Barcelona-Buenos Aires-México, Paidós, 2000, p. 213-217.

Kanzepolsky, Adriana, “'Aquí llegamos, aquí no veníamos', acerca de El ghetto de Tamara Kamenszain”. Hispamérica, Año 39, No. 115 (Abril 2010), p. 103-112.

Laboy, Edwin M. (ed.), La interrogación incesante (entrevistas 1996-2012). Mercedes Roffé, Madrid, Amargord, 2013.

León, Denise, “La mirada de Ruth. Fabulaciones del linaje en la poesía de Tamara Kamenszain”, Anales de Literatura Hispanoamericana, vol. 38, 2009, p. 341-352.

Lévinas, Emmanuel, Difficile liberté, Paris, Albin Michel, 1976.

Lukin, Liliana, La Ética demostrada según el orden poético, Buenos Aires, La Cebra, 2014.

--- L'Éthique démontrée selon l'ordre poétique, Poèmes traduits de l'espagnol par Jacques Ancet, Paris, Caractères, 2014.

Masiello, Francine. "Poesía y ética”, Revista de Crítica Literaria Latinoamericana, Año 33, No. 65 (2007), p. 11-25.

Misrahi, Robert, Spinoza et le spinozisme, Paris, Armand Collin, 2000.

Morin, Edgar, Le monde moderne et la condition juive, Paris, Seuil, 2006.

Ouaknin, Marc-Alain, Tsimtsoum. Introduction à la méditation hébraïque, Paris, Albin Michel, 1992.

Rives, Ayelén, "Liliana Lukin: poética contra lo irreparable”, Entrevista por Ayelén Rives. Lamás médula, Nov 10, 2016. Web.

Roffé, Mercedes, Canto errante. Seguido de Memorial de agravios, Con prólogo de Raúl Zurita, Madrid, Amargord, 2011.

--- Las linternas flotantes, Buenos Aires, Bajo la luna, 2009.

Saccal, Rita, History of Jewish Publishing in Argentina, Artículo en línea: http:// databases.jewishlibraries.org/sites/default/files/proceedings/proceedings2005/saccal.pdf [recuperado 01/05/2017]

\section{NOTAS}

1. Como para las otras citas en español, la traducción es mía. He aquí la versión original: “Assimil é pour les uns, inassimilable pour les autres, le juif sent en lui une étrangeté, et par rapport à la religion de Moïse dont il est détaché, et par rapport au monde des gentils où persistent mille formes de rejets. Ainsi est-il contraint à une double et trouble identité. Le nom juif a cessé pour lui d'être substantif, c'est un adjectif qui le rattache à un passé de traditions perdues et de persécutions pouvant sans cesse renaître" (212).

2. "la quasi absence de la religión dans un corpus littéraire qui touche à l'identité juive est un indice significatif d'une manière fort laïque de concevoir la judéité” (214).

3. Fridman apunta que se trata de un imaginario literario anterior o contemporáneo de los atentados de 1992 y 1994 que marcan un hito en la vida de la comunidad judeoargentina. En la sociedad se observa una tendencia a la reafirmación de esta identidad después de los atentados.

4. La judeidad en la Argentina tiene al marrano como emblema (256).

5. "le travail sociogrammatique des textes littéraires examinés se situe dans un dépassement de [l'] opposition [entre assimilation et ghettoïsation], dans la figure de l'hybridité".

6. Véase al respecto el artículo de Denise León. 
7. DRAE gueto. Del it. ghetto. Acepciones 2 y 3: “2. m. Barrio o suburbio en que viven personas marginadas por el resto de la sociedad. 3. m. Situación o condición marginal en que vive un pueblo, una clase social o un grupo de personas".

8. Pero la transmisión de la tradición a su hijo deja a la hablante lírica con un " peso » que no deshace ninguna ironía. Cito del poema "Bar Mitzvá": "Me pesa el muro que te cargo/ con la vista puesta en la espalda/ el horizonte nos señala/ otra patria.[...]/ demasiado familiar para tanta lejanía/ cuando el muchacho judío se consagra/ un tránsito pesado/ entre el país que arranca de su infancia/ y la tierra prometida/ me deja lejos" (280).

9. Existe una referencia irónica a Freud en el poema epónimo (292).

10. Este poema sería el reverso del soneto de C. Vallejo ("Piedra blanca sobre una piedra negra ") que evoca la muerte futura del poeta: "Me moriré en París con aguacero,/un día de cual tengo ya el recuerdo./ Me moriré en París -y no me corro-/ tal vez un jueves, como es hoy, de otoño. [...]". 11. Véase la entrevista de Roffé por Laboy (238).

12. Raúl Zurita en Roffé 2011: 10.

13. Acerca de la intertextualidad en la poesía de Roffé, es interesante este comentario de Francine Masiello: "El contrato intertextual de Roffé es mucho más que una simple serie de préstamos; de hecho, está pensado para funcionar a través de una teoría de acumulación de las formas, con la cual se yuxtaponen fragmentos de sonidos e imágenes para luego encontrar un tema que se podrá compartir con otros, un tema que vaya más allá de cualquier texto específico y que de hecho excede los límites marcados por el suyo. La espectralidad de las formas y de las imágenes previas nos guían, por consiguiente, hacia el significado futuro" (Masiello 15) .

14. La tipografía es la del original. Las letras hebraicas significan: אבי = Abi, "mi padre ".

15. "[a]près le Tsimtsoum, la lumière divine jaillit dans l'espace vide sous forme d'un rayon en ligne droite" (Ouaknin 32).

16. "Entonces.../ si era todo mentira/ si -es cierto-/ era todo mentira.../ Entonces:/podemos asistirnos./ Presenciarnos./ Un pacto no pequeño./ (¿Qué más darse?)” (37).

17. "En el origen fue el Bien./ Y de él, todas las cosas" (65).

18. Sería también el caso de la propia Kamenzsain, mientras que Roffé no aparece en las listas de Saccal.

19. Citado por Lukin (82).

20. Véase al respecto el libro de Fabry (2008).

21. "La démarche de Spinoza consistera donc en une critique du dualisme. De même qu'il avait contesté la division du réel en un Dieu créateur et un monde créé, il conteste la doctrine cartésienne de l'homme, défini comme l'union entre une âme et un corps". (Misrahi 34)

22. “ [L'homme] est constitué, comme toute chose, par l'individuation de ces deux aspects de la substance que sont la Pensée et l'Étendue : il est un individu unifié comportant un aspect Pensée et un aspect Étendue (matière), ces deux aspects étant ceux d'un seul être. Plus précisément, l'homme est l'unité contemporaine d'un mode fini de la Pensée (une idée) et d'un mode fini de 1 'Étendue (un corps). La signification concrète de ces définitions techniques est celle-ci: l'individu humain est d'un seul tenant corps et esprit, ces deux aspects exprimant dans leur registre respectif une seule réalité". (Misrahi 34-35). 


\section{RESÚMENES}

En este artículo, se estudiará un corpus de poemarios del siglo XXI, publicados por autoras argentinas nacidas alrededor de 1950 y que reconocen una herencia judía en su historia personal: El ghetto de Tamara Kamenszain (2003), Canto errante y Memorial de agravios (2002) de Mercedes Roffé y Ética demostrada según el orden poético de Liliana Lukin (2011). Cabrá preguntarse qué rasgos de "lo judío" (Morin) se manifiestan en esta poesía: ¿religión, cultura o sensibilidad? En los poemarios considerados, se repite el gesto de la escritura vinculado con la memoria de un aspecto del legado religioso y cultural judío que los sujetos líricos de los poemas invitan al mismo tiempo a reconocer como propio y a problematizar.

Dans cet article, on étudiera un corpus de recueils poétiques du XXIe s., publiés par des écrivaines argentines nées aux alentours de 1950 et qui reconnaissent un héritage juif dans leur histoire personnelle : El ghetto de Tamara Kamenszain (2003), Canto errante y Memorial de agravios (2002) de Mercedes Roffé et Ética demostrada según el orden poético de Liliana Lukin (2011). Il conviendra de se demander quels traits de la judéité se manifestent dans cette poésie : religion, culture ou sensibilité ? Dans les recueils considérés, se répète le geste de l'écriture lié à la mémoire d'un héritage religieux et culturel juif que les sujets lyriques des poèmes invitent à la fois à reconnaître comme propre et à problématiser.

This article is composed of the analysis of a corpus of $21^{\text {st }}$ century poetry collections published by Argentinian female authors born around the 1950s and embracing their Jewish inheritance in their stories: Tamara Kamenszain's El ghetto (2003), Mercedes Roffé's Canto errante y Memorial de agravios (2002) and Liliana Lukin's Ética demostrada según el orden poético (2011). What is at stake is to be able to determine which facets of the Jewish identity this poetry embodies : either religious, cultural or sensible ones? In these collections under study, the act of writing through the remembrance of a cultural and religious Jewish inheritance is repeated so as to invite oneself to embrace and to reflect upon these lyrical topics.

\section{ÍNDICE}

Palabras claves: Poesía, judeidad, Argentina, identidad, expulsión

Keywords: Poetry, Jewish, identity, rejection, Argentina.

Mots-clés: Poésie, judéité, Argentine, identité, expulsión

\section{AUTOR}

\section{GENEVIÈVE FABRY}

Université catholique de Louvain (Louvain-la-Neuve, Belgique)

genevieve.fabry@uclouvain.be 